\title{
Combined Exposure to Nicotine and Ethanol in Adolescent Mice Differentially Affects Anxiety Levels during Exposure, Short-Term, and Long-Term Withdrawal
}

\author{
Yael Abreu-Villaça*,', Fernanda Nunes', Fabíola do E Queiroz-Gomes', Alex C Manhães' and \\ Cláudio C Filgueiras' \\ 'Laboratório de Neurofisiologia, Departamento de Ciências Fisiológicas, Instituto de Biologia Roberto Alcântara Gomes, Centro Biomédico, \\ Universidade do Estado do Rio de Janeiro, Rio de Janeiro, Brazil
}

\begin{abstract}
Smoking and consumption of alcoholic beverages are frequently associated during adolescence. This association could be explained by the cumulative behavioral effects of nicotine and ethanol, particularly those related to anxiety levels. However, despite epidemiological findings, there have been few animal studies of the basic neurobiology of the combined exposure in the adolescent brain. In the present work we assessed, through the use of the elevated plus maze, the short- and long-term anxiety effects of nicotine (NIC) and/or ethanol $(\mathrm{ETOH})$ exposure during adolescence (from the 30th to the 45th postnatal day) in four groups of male and female C57BL/6 mice: ( 1 ) Concomitant NIC (nicotine free-base solution $(50 \mu \mathrm{g} / \mathrm{ml})$ in $2 \%$ saccharin to drink) and ETOH (ethanol solution $(25 \%, 2 \mathrm{~g} / \mathrm{kg})$ i.p. injected every other day) exposure; (2) NIC exposure; (3) ETOH exposure; (4) Vehicle. C57BL/6 mice were selected, in spite of the fact that they present slower ethanol metabolism, because they readily consume nicotine in the concentration used in the present study. During exposure (45th postnatal day: PN45), our results indicated that ethanol was anxiolytic in adolescent mice and that nicotine reverted this effect. Short-term drug withdrawal (PN50) elicited sex-dependent effects: exposure to nicotine and/or ethanol was anxiogenic only for females. Although neither nicotine nor ethanol effects persisted up to I month postexposure (PN75), the coadministration elicited an anxiogenic response. In spite of the fact that generalizations based on the results from a single strain of mice are prone to shortcomings, our results suggest that the deficient response to the anxiolytic effects of ethanol in adolescents co-exposed to nicotine may drive higher ethanol consumption. Additionally, increased anxiety during long-term smoking and drinking withdrawal may facilitate relapse to drug use. Neuropsychopharmacology (2008) 33, 599-6I0; doi:I0.1038/sj.npp. I30I429; published online 25 April 2007
\end{abstract}

Keywords: anxiogenic; anxiolytic; development; tobacco; alcohol

\section{INTRODUCTION}

Tobacco and ethanol are the most commonly abused drugs and, as indicated by epidemiological studies, tobacco smoking and alcohol drinking very often occur concomitantly. The majority (between 80 and 95\%) of alcoholics smoke and $70 \%$ of alcoholics are heavy smokers, compared with the $10 \%$ in the population as a whole. In addition, smokers consume twice as much alcohol as do nonsmokers and alcoholics who smoke consume more cigarettes than do nonalcoholic smokers (Carmody et al, 1985; Dawson, 2000; DiFranza and Guerrera, 1990; Larsson and Engel, 2004;

\footnotetext{
*Correspondence: Dr Y Abreu-Villaça, Laboratório de Neurofisiologia, Departamento de Ciências Fisiológicas, Instituto de Biologia Roberto Alcântara Gomes, Centro Biomédico, Universidade do Estado do Rio de Janeiro, Av. Prof. Manuel de Abreu 444, 5 andar, Vila Isabel, Rio de Janeiro, RJ 20550-170, Brazil, Tel: +552I 2587 6295, Fax: +552I 2587 6129, E-mail: yael_a_v@yahoo.com.br

Received 6 December 2006; revised 2 March 2007; accepted 21 March 2007
}

Patten et al, 1996). Adolescence is the critical period during which most smokers begin their habit (National Institute on Drug Abuse, 1998; Nelson et al, 1995). Exploratory alcohol use also typically occurs during adolescence (Spear, 2000). Perhaps most importantly, there is a strong correlation between onset of tobacco consumption at an early age and alcohol addiction, characterizing adolescence as a period of vulnerability (Grant, 1998). Accordingly, a better understanding of the frequent association between nicotine and alcohol consumption during adolescence is an important area of research, since it could help elaborate intervention strategies to decrease the co-abuse.

Studies of adult smokers have shown that tobacco can reduce anxiety, suggesting that smokers continue smoking to regulate anxiety state (Gilbert et al, 1989; Picciotto et al, 2002; Pomerleau, 1986). In contrast, adolescent smokers report increased levels of anxiety during exposure, even though it has been suggested that anxiety is also a symptom of nicotine withdrawal (Hughes et al, 2000; Parrot, 2003). Since it has been hypothesized that anxiety levels play a role 
in the maintenance of smoking, it is reasonable to suggest that anxiety levels associated with smoking and smoking abstinence may play an important role in adolescent tobacco use. Studies in animal models have reported both anxiolytic (Brioni et al, 1993) and anxiogenic (Ouagazzal et al, 1999) effects of nicotine. In accordance with the aforementioned differences between adolescent and adult human smokers, these conflicting patterns of response seem to depend on the age (adolescence $v s$ adulthood) (Elliott et al, 2004; Smith et al, 2006). In addition, the regimen of administration, nicotine dose, sex, species/strain, and the method of assessing anxiety may also play a role (Adriani et al, 2004; Balerio et al, 2006; Cheeta et al, 2001; Elliott et al, 2004; Marco et al, 2006; Slawecki et al, 2003; Smith et al, 2006).

The anxiolytic-like profile of alcohol has been widely recognized as an important factor in alcohol abuse. Excessive alcohol consumption by anxious patients, presumably due to the anxiolytic properties of alcohol, has led to the hypothesis that anxiety could be a critical factor in the etiology of alcohol drinking (Colombo et al, 1995). The anxiolytic-like effects of ethanol associated with forced and acute administration (Bilkei-Gorzo et al, 1998; Ferreira et al, 2000; Hall et al, 1998; Martijena et al, 2001; Varlinskaya and Spear, 2002) or voluntary ethanol consumption (Colombo et al, 1995; Gallate et al, 2003) have been extensively described in different rodent tests. In addition, in contrast to the effect described during exposure, the occurrence of an anxiogenic-like effect during ethanol withdrawal has been reported (Kliethermes, 2005). Recent studies have demonstrated that the effects of ethanol are dependent on the age of exposure, so that ethanol exposure differentially affects adolescents and adults. Adolescent rodents may be hyposensitive to ethanol effects that may serve as cues to modulate intake, such as anxiolysis during exposure and anxiogenic manifestations of withdrawal (Doremus et al, 2003; Spear and Varlinskaya, 2005; Varlinskaya and Spear, 2004), however, effects of ethanol on anxiety-related behaviors are still controversial. Particularly, in contrast to these previous findings, recent studies have shown that ethanol elicits a more prominent anxiogenic response after adolescent exposure (Popovic et al, 2004; Slawecki et al, 2004; Slawecki and Ehlers, 2005).

In spite of the epidemiological findings indicating a frequent association between tobacco and alcohol consumption (Carmody et al, 1985; Dawson, 2000; DiFranza and Guerrera, 1990; Grant, 1998; Larsson and Engel, 2004; Patten et al, 1996), there is scant information as to the behavioral consequences of interactions of nicotine and ethanol during adolescence. Accordingly, the purpose of the current study was to examine the effects of adolescent nicotine and/or ethanol administration on anxiety levels during drug administration and withdrawal. Regular smokers tend to smoke intermittently in order to maintain blood levels of nicotine above a minimum effective concentration during their active period, therefore, we chose to give animals free access to a nicotine solution in the drinking water, which allows for consumption during their active time. As for ethanol, we chose a moderate dose to be injected (i.p.) every other day, mimicking adolescents binge drinking. The elevated plus maze (EPM), a reliable instrument for the analysis of anxiety-like behavior (Carobrez and Bertoglio, 2005) was used to assess anxiety levels during drug exposure and at different ages up to 1 month after the initiation of withdrawal.

\section{METHODS}

\section{Animal Treatment and Behavioral Testing}

All experiments were carried out in accordance with the declaration of Helsinki and with the Guide for the Care and Use of Laboratory Animals as adopted and promulgated by the National Institutes of Health. C57BL/6 mice were chosen because prior reports demonstrate that adult and periadolescent mice from this strain consume nicotine in the concentration used in the present study (Klein et al, 2003, 2004; Sparks and Pauly, 1999). All mice were bred and maintained in our laboratory. The animals were kept in a temperature-controlled room on a $12 \mathrm{~h}$ light/dark cycle (lights on at 0200). Access to food and water was ad lib. On the first postnatal day (PN1), litters were culled to a maximum of eight mice to ensure standard nutrition. At weaning (PN25), animals were separated by sex and allowed free access to food and water.

On PN29, pups from 55 litters (128 females and 135 males) were individually housed. Single housing may influence animals' behavior (Douglas et al, 2003; Vanderschuren et al, 1997), however, it allowed for accurate measurement of fluid intake/nicotine consumption for each animal. Animals were exposed to nicotine and/or ethanol from PN30 to PN45, the approximate age range during which animals of both genders and most breeding stock exhibit adolescent-typical behavioral characteristics and particular neurochemical and endocrine patterns when compared to adulthood and prepubertal periods (Spear, 2000). During this period, (-)-nicotine freebase $(50 \mu \mathrm{g} / \mathrm{ml}$ ) (Sigma, St Louis, MO) in $2 \%$ saccharin or $2 \%$ saccharin only was administered in the drinking water (the sole source of fluid) in order to mimic continuous nicotine consumption; while $25 \%$ ethanol $(2 \mathrm{~g} / \mathrm{kg})$ solution $(\mathrm{v} / \mathrm{v})$ in saline or saline only was injected (i.p.) every other day in order to mimic cyclical patterns of alcohol consumption. Accordingly, male and female mice from each litter were distributed into four treatment groups: $\mathrm{VEH}$ (oral saccharin + injected saline), NIC (oral nicotine/saccharin + injected saline), ETOH (oral saccharin + injected ethanol), and those receiving the combined treatment: NIC + ETOH (oral nicotine/saccharin + injected ethanol). Bottles were cleaned and refilled daily. Loss due to leakage was measured from a bottle placed in an empty cage ('blank') and subtracted from fluid consumption data. Body weights and fluid consumption were also measured every day. Since body weight increases significantly during adolescence, daily fluid intake data were obtained by dividing the absolute values of fluid intake of each animal by its own body weight.

Animals were submitted to the EPM at three different time points, one at the end of the drug administration period (PN45), and the other two at 5 days and 1 month after the end of the drug exposure period (PN50 and PN75, respectively). For mice assigned to the PN45 group, in order to avoid acute effects due to drug exposure, such as motor impairment, the last ethanol injection was administered 1 day before the test. The EPM is shaped like a plus sign and consists of two 'open' (no walls, $5 \times 29 \mathrm{~cm}$ ) and two 'closed' 
$(5 \times 29 \times 15 \mathrm{~cm})$ arms arranged perpendicularly and elevated $50 \mathrm{~cm}$ above the floor. The test began with the animal being placed on the center of the equipment, facing a closed arm. Each test lasted $10 \mathrm{~min}$ and all testing sessions were performed between 0300 and 0700 in a sound attenuated room. All tests were videotaped and the total time spent in the open arms (Time OA), the percentage of time spent in the open arms (\%Time OA: the time spent in open arms divided by time spent in open + closed arms), and the number of open arms entries (Entries OA) were used as anxiety measures (Elliott et al, 2004; Ferandes and File, 1996; Hogg, 1996; Rodgers and Dalvi, 1997). Considering that Entries OA is related to levels of locomotor activity, and that locomotor activity may be affected by activation or suppression effects of nicotine and ethanol, the percentage of open arms entries (\%Entries OA: the number of entries in open arms divided by number of entries in open + closed arms (Entries $\mathrm{OA}+\mathrm{CA}$ ), an index that corrects for altered locomotor activity, was also used as a measure of anxiety (Elliott et al, 2004; Ferandes and File, 1996; Hogg, 1996; Rodgers and Dalvi, 1997). Entries OA + CA was used as a measure of activity. All the variables were scored using the video images of the tests.

\section{Data Analysis}

Data are compiled as means and standard errors. To reduce the likelihood of type 1 statistical errors that might result from repeated testing of the global data set, results of longitudinal studies were evaluated first by a global repeated-measures analyses of variance, rANOVA, (data log transformed whenever variance is heterogeneous) on all factors (nicotine and/or ethanol TREATMENT, AGE, SEX). For nicotine consumption, effects of nicotine and/or ethanol TREATMENT on body weights and on fluid intake divided per body weight (fluid intake/body weight), DAY was considered the within-subjects factor. The ANXIETY MEASURES (Time OA, \%Time OA, Entries OA, \%Entries $\mathrm{OA})$ were also treated as repeated measures, since each was obtained from the same animal at each age.

Appropriate lower-order ANOVAs were utilized whenever significant interactions of TREATMENT with other factors were detected. These determinations were made before deciding whether to pool values from animals of both sexes within each treatment group. Individual group or age differences were evaluated post hoc by Fisher's protected least significant difference (FPLSD). However, whenever treatment effects did not interact with other factors, only the main effect was recorded. Significance is assumed at the level of $P<0.05$ for main effects and at $P<0.1$ for interactions. We also examined whether lower-order main effects were detectable after subdivision of the interactive factors (Snedecor and Cochran, 1967).

The study design required two different ways of regarding treatment factors. To compare the effects of nicotine exposure alone, ethanol exposure alone, or the combined exposure to controls or to each other, the four treatment groups were considered as a one-dimensional factor (TREATMENT) in the statistical design. To determine whether the effects of nicotine exposure and ethanol exposure were interactive, the treatment factors were changed to a two-dimensional design (two factors: NICOTINE treatment and ETHANOL treat- ment). In this formulation, more-than-additive (synergistic) and less-than-additive effects appear as significant interactions between the two treatment dimensions, whereas simple, additive effects do not show significant interactions (AbreuVillaça et al, 2004a, b; Rhodes et al, 2003).

Activity effects (Entries OA + CA) were evaluated with analysis of variance (ANOVA) (nicotine and/or ethanol TREATMENT, AGE, SEX were used as factors).

Considering that animals had $a d$ lib access to the nicotine solution, variations in the amount of nicotine received were to be expected. The normality of the distributions of average daily nicotine consumption per animal was assessed by means of Kolmogorov-Smirnov one-sample tests (K-S). In order to verify whether there were significant associations between the total amount of nicotine received and the behavioral variables, Kendall's correlation coefficients $(\tau)$ were calculated. The analysis was carried out initially using the entire data set and subsequently segmenting the data set into TREATMENT (NIC and NIC+ETOH); AGE (PN45, PN50, and PN75); and SEX groups.

\section{RESULTS}

\section{Effects on Fluid Intake/Body Weight, Nicotine Consumption, and Body Weight}

As indicated by the rANOVA, fluid intake/body weight increased throughout the experiment (DAY: $F=90.6$, $\mathrm{df}=14, P<0.0001$; days 1 through 5: $0.26 \pm 0.004 \mathrm{ml} / \mathrm{g}$; days 6 through 10: $0.32 \pm 0.003 \mathrm{ml} / \mathrm{g}$; days 11 through 15: $0.35 \pm 0.003 \mathrm{ml} / \mathrm{g}$ ). Overall fluid intake/body weight was affected by TREATMENT $(\mathrm{F}=8.4, \mathrm{df}=3, P<0.0001)$ in a sex-dependent way (TREATMENT $\times$ SEX interaction: $\mathrm{F}=3.3, \mathrm{df}=3, P<0.02)$. After separation by sex, we found significant TREATMENT effects only for females $(F=8.5$, $\mathrm{df}=3, \quad P<0.0001)$ with a rank order of $\mathrm{VEH}>\mathrm{NIC}=$ ETOH $>$ NIC + ETOH. Nicotine exposure elicited a significant reduction in fluid intake/body weight relative to the VEH group $(P<0.004$, FPLSD), suggestive of an aversive taste effect specific for females. A reduction of similar magnitude (since NIC $=\mathrm{ETOH}, P=0.43$, FPLSD) was also identified for the ETOH when compared to the VEH group $(P<0.02$, FPLSD), indicating that ethanol injections also negatively affected fluid intake. Females receiving the combined treatments showed a significant fluid intake/ body weight reduction relative to the NIC $(P<0.04$, FPLSD), ETOH $(P<0.02$, FPLSD $)$ and VEH $(P<0.0001$, FPLSD $)$ groups that reflected additive nicotine and ethanol effects (no interaction of NICOTINE $\times$ ETHANOL treatments in the two-dimensional design ANOVA) (Table 1).

Similarly, nicotine consumption significantly increased (DAY: $\mathrm{F}=39.1, \mathrm{df}=14, P<0.0001$ ) throughout the experiment (days 1 through 5: $12.4 \pm 0.2 \mathrm{mg} / \mathrm{kg}$; days 6 through 10: $15.2 \pm 0.2 \mathrm{mg} / \mathrm{kg}$; days 11 through $15: 16.5 \pm 0.2 \mathrm{mg} / \mathrm{kg})$. We also found interactions of TREATMENT $\times \operatorname{SEX}(\mathrm{F}=2.8$, $\mathrm{df}=1, P<0.1)$ and of DAY $\times$ TREATMENT $\times \operatorname{SEX}(\mathrm{F}=1.5$, $\mathrm{df}=14, P<0.09)$. After separation of the values by sex, we also found significant TREATMENT effects only for females $(\mathrm{F}=4.9, \mathrm{df}=1, P<0.04)$, reflecting reductions in nicotine consumption for the $\mathrm{NIC}+\mathrm{ETOH}$ when compared to the NIC group restricted to the third $(P<0.004$, FPLSD) and ninth $(P<0.03$, FPLSD) days of exposure. As expected, daily 
nicotine consumption in the NIC and NIC + ETOH groups varied from animal to animal. The distributions of consumption data were clearly normal for both groups (NIC K-S: $Z=0.6, P>0.1 ; \quad \mathrm{NIC}+\mathrm{ETOH} \quad \mathrm{K}-\mathrm{S}: \quad Z=0.7$, $P>0.1)$. The analysis of the Kendall's correlation coefficients indicated that the variations in the amount of nicotine that the animals (NIC and NIC+ETOH groups) consumed were not associated with any of the behavioral variables $(\tau<0.1, P>0.1$ in all cases).

In spite of treatment and sex differences in fluid intake/ body weight and in nicotine consumption, body weight gain was not affected by TREATMENT (no effect or interactions were observed).

\section{Overall Statistical Analysis of Anxiety Measures}

Considering the four treatments in a one-dimensional design rANOVA, we found significant interactions of TREATMENT $\times$ AGE, TREATMENT $\times$ ANXIETY MEASURES, TREATMENT $\times$ ANXIETY MEASURES $\times$ AGE. With the NICOTINE and ETHANOL treatments considered as separate factors in a two-dimensional design, we again

Table I Fluid Intake/Body Weight, Nicotine Consumption, and Body Weight Data

\begin{tabular}{|c|c|c|c|c|}
\hline Measure & VEH & NIC & ETOH & NIC+ETOH \\
\hline \multicolumn{5}{|c|}{ Fluid intake/body weight (ml/g) } \\
\hline Male & $0.31 \pm 0.01$ & $0.29 \pm 0.01$ & $0.31 \pm 0.01$ & $0.29 \pm 0.01$ \\
\hline Female & $0.37 \pm 0.02$ & $0.32 \pm 0.02^{\mathrm{a}, \mathrm{b}}$ & $0.32 \pm 0.01^{a, b}$ & $0.28 \pm 0.0 l^{\mathrm{a}}$ \\
\hline \multicolumn{5}{|c|}{ Nicotine consumption (mg/kg) } \\
\hline Male & - & $14.7 \pm 0.50$ & - & $14.6 \pm 0.45$ \\
\hline Female & - & $15.7 \pm 0.75^{b}$ & - & $13.8 \pm 0.45$ \\
\hline \multicolumn{5}{|c|}{ Body weight (g) } \\
\hline Male & $14.5 \pm 0.45$ & $14.7 \pm 0.48$ & $13.8 \pm 0.44$ & $14.2 \pm 0.43$ \\
\hline Female & $13.2 \pm 0.35$ & $13.1 \pm 0.39$ & $12.4 \pm 0.34$ & $12.7 \pm 0.33$ \\
\hline
\end{tabular}

Abbreviations: $\mathrm{ETOH}$, ethanol exposure group; NIC, nicotine exposure group; $\mathrm{NIC}+\mathrm{ETOH}$, nicotine and ethanol exposure group; VEH, vehicle group.

${ }^{a} V$ alues for which there were significant differences when compared to the VEH group.

bValues for which there were significant differences when compared to the $\mathrm{NIC}+\mathrm{ETOH}$ group (mean \pm SEM). found interactions indicative of NICOTINE- or ETHANOLselective effects. Furthermore, NICOTINE and ETHANOL treatments interacted with each other, and with ANXIETY MEASURES. Given the interaction of each treatment with the type of measurement, and age, we separated the data into the individual anxiety measures and age and then reexamined the results. Treatments were also interactive with sex, so after subdividing the data, we kept this variable in the analysis to see whether treatment interactions remained detectable (Table 2).

\section{Anxiety Effects}

On PN45 (Figure 1a-d), with TREATMENT considered as a one-dimensional factor, main TREATMENT effects on Time $\mathrm{OA}(\mathrm{F}=3.3, \mathrm{df}=3, P<0.03)$ and on $\%$ Entries $\mathrm{OA}(\mathrm{F}=3.7$, $\mathrm{df}=3, P<0.02)$ were detected. Ethanol exposure elicited an increase in Time OA $(P<0.02$, FPLSD $)$ and \%Entries OA $(P<0.01$, FPLSD $)$ relative to the VEH group; thus, ethanol elicited an anxiolytic response. Animals receiving the combined treatment showed reduced Time OA $(P<0.007$, FPLSD $)$ and \%Entries OA $(P<0.003$, FPLSD) values when compared to the ETOH group. There was also a trend for decreased Time OA in the NIC + ETOH when compared to the NIC group $(P=0.06$, FPLSD). Using the twodimensional design (NICOTINE and ETHANOL treatments considered as separate factors in the ANOVA), we found NICOTINE $\times$ ETHANOL interactions for all anxiety measures: Time $\mathrm{OA}(\mathrm{F}=9.1, \mathrm{df}=1, P<0.004)$, \%Time $\mathrm{OA}$ $(\mathrm{F}=6.7, \quad \mathrm{df}=1, \quad P<0.02)$, Entries $\mathrm{OA} \quad(\mathrm{F}=7.4, \quad \mathrm{df}=1$, $P<0.009)$, and $\%$ Entries $\mathrm{OA}(\mathrm{F}=8.9, \mathrm{df}=1, P<0.004)$, indicative of less-than-additive effects of NICOTINE and ETHANOL: the anxiolytic effects of ethanol were reduced by nicotine co-exposure. There were no SEX effects or TREATMENT $\times$ SEX interactions.

For Entries OA + CA (Figure 1e), the ANOVA detected a main TREATMENT effect $(\mathrm{F}=4.3, \mathrm{df}=3, P<0.008)$. In keeping with previous data (Saito et al, 2005; Ulusu et al, 2005), nicotine exposure alone elicited increased locomotor activity $\quad(\mathrm{NIC}>\mathrm{VEH}, \quad P<0.02 ; \quad \mathrm{NIC}>\mathrm{ETOH}, \quad P<0.005$; FPLSD). However, ethanol treatment reversed the nicotineinduced increase in locomotor activity as indicated by the significant difference between values for the nicotine and combined exposure groups (NIC $>$ NIC + ETOH, $P<0.002$; FPLSD) and by the less-than-additive effect of NICOTINE and ETHANOL detected by the NICOTINE $\times$ ETHANOL

Table 2 Overall Analysis of Anxiety Effects

\begin{tabular}{|c|c|c|c|}
\hline Effect & One-dimensional design & Effect & Two-dimensional design \\
\hline Treatment $\times$ age & $\mathrm{F}=3.6, \mathrm{df}=6, P<0.002$ & Ethanol treatment $\times$ age & $F=2.6, d f=2, P<0.08$ \\
\hline Treatment $\times$ age $\times$ sex & $F=2.0, d f=6, P<0.06$ & Ethanol treatment $\times$ age $\times$ se $x$ & $\mathrm{~F}=2.4, \mathrm{df}=2, P<0.09$ \\
\hline Treatment $\times$ measures $\times$ age & $F=3.3, d f=|8, P<0.000|$ & Nicotine treatment $\times$ measures & $\mathrm{F}=2.2, \mathrm{df}=3, P<0.09$ \\
\hline Treatment $\times$ measures $\times$ age $\times$ se $x$ & $F=2.1, d f=18, P<0.007$ & Nicotine treatment $x$ measures $x$ age $x$ sex & $\mathrm{F}=2.0, \mathrm{df}=6, P<0.07$ \\
\hline
\end{tabular}

Measures refer to the four anxiety measures (Time OA, \%Time OA, Entries OA, \%Entries OA). The main effects and interaction terms that showed no significant differences are not shown in the table. 


\section{PN45}
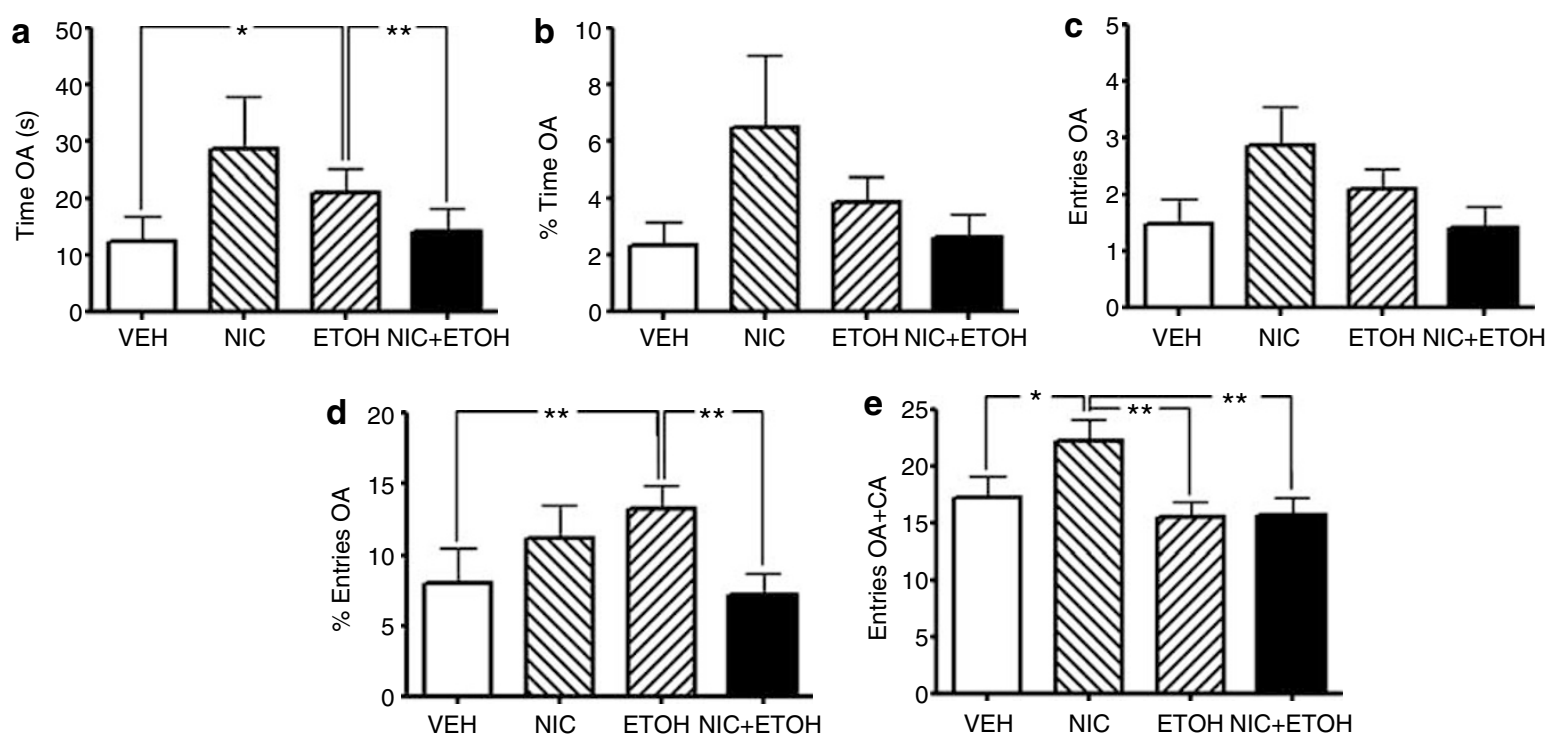

Figure I Effects of adolescent nicotine and/or ethanol treatment on anxiety levels (a-d) and locomotor activity (e) measured in the EPM during exposure (PN45). (a) Time spent in the open arms (Time OA). (b) Percentage of time spent in the open arms (\%Time OA). (c) Number of open arms entries (Entries OA). (d) Percentage of open arms entries (\%Entries OA). (e) Number of open arms + closed arms entries (Entries OA + CA). Values are means \pm SEM. $\mathrm{VEH}$, vehicle group; $\mathrm{NIC}$, nicotine exposure group; $\mathrm{ETOH}$, ethanol exposure group; $\mathrm{NIC}+\mathrm{ETOH}$, nicotine and ethanol exposure group. $* P<0.05$, *** $P<0.01$, significant difference between groups as revealed by FPLSD.

interaction in the two-dimensional design $(\mathrm{F}=3.4, \mathrm{df}=1$, $P<0.06)$.

On PN50 (Figure 2a-d), with TREATMENT considered as a one-dimensional factor, the ANOVA detected significant TREATMENT $\times$ SEX interactions for Time OA $(\mathrm{F}=2.3$, $\mathrm{df}=3, P<0.09)$ and \%Time $\mathrm{OA}(\mathrm{F}=2.5, \mathrm{df}=3, P<0.07)$. After separation by sex, we found significant TREATMENT effects only for females: Time $\mathrm{OA}(\mathrm{F}=3.6, \mathrm{df}=3, P<0.03)$; \%Time $\mathrm{OA}(\mathrm{F}=4.2, \mathrm{df}=3, P<0.02)$. Females receiving nicotine (Time OA: $P<0.01, \%$ Time OA: $P<0.005$, FPLSD); ethanol (Time OA: $P<0.02$, \%Time OA: $P<0.01$, FPLSD); or the combined treatment (Time OA: $P<0.05$, \%Time OA: $P<0.03$, FPLSD) presented reduced values when compared to the VEH group, thus indicating a consistent anxiogenic response. With NICOTINE and ETHANOL treatments considered as two dimensions, females presented NICOTINE $\times$ ETHANOL interactions for Time $\mathrm{OA}(\mathrm{F}=5.0, \mathrm{df}=1$, $P<0.03)$ and \%Time $\mathrm{OA}(\mathrm{F}=5.9, \mathrm{df}=1, P<0.02)$, thus indicating less-than-additive effects of NICOTINE and ETHANOL. There were no significant alterations on the activity measure (Entries $\mathrm{OA}+\mathrm{CA}$; Figure $2 \mathrm{e}$ ).

On PN75, 1 month after the end of treatment (Figure $3 a-d)$, with a one-dimensional arrangement of the TREATMENT factors, the ANOVA detected significant TREATMENT effects for all anxiety measures: Time $\mathrm{OA}(\mathrm{F}=3.2$, $\mathrm{df}=3, \quad P<0.03) ; \%$ Time $\mathrm{OA}(\mathrm{F}=3.0, \mathrm{df}=3, \quad P<0.04)$; Entries $\mathrm{OA}(\mathrm{F}=3.5, \mathrm{df}=3, P<0.02)$; and \%Entries $\mathrm{OA}$ $(\mathrm{F}=2.8, \mathrm{df}=3, P<0.05)$. Animals receiving the combined treatment presented reduced values when compared to the VEH (Time OA: $P<0.02$, \%Time OA: $P<0.04$, Entries OA, and \%Entries OA: $P<0.03$, FPLSD); NIC (Time OA: $P<0.02$, \%Time OA: $P<0.009$, Entries OA: $P<0.003$, \%Entries OA: $P<0.02$, FPLSD); and ETOH (Time OA and \%Entries OA: $P<0.02$, FPLSD) groups, thus indicating a consistent anxiogenic response due to the combined exposure. Expanding the analysis to consider NICOTINE and ETHANOL treatments as two separable factors, we identified significant NICOTINE $\times$ ETHANOL interactions for Time $\mathrm{OA}(\mathrm{F}=2.8, \mathrm{df}=1, P<0.1)$; Entries $\mathrm{OA}(\mathrm{F}=3.5$, $\mathrm{df}=1, P<0.07)$; and $\%$ Entries $\mathrm{OA}(\mathrm{F}=3.3, \mathrm{df}=1, P<0.08)$. The significant interaction of the two treatments indicated that the effect of combined nicotine and ethanol treatment could not be statistically accounted for by the summation of the two individual sets of effects: although neither nicotine nor ethanol alone elicited significant changes on anxiety measures when compared to the vehicle group (VEH), there was significant reductions in Time $\mathrm{OA}(\mathrm{F}=2.8, \mathrm{df}=1$, $P<0.1)$; Entries $\mathrm{OA}(\mathrm{F}=3.5, \mathrm{df}=1, P<0.07)$; and \%Entries $\mathrm{OA}(\mathrm{F}=2.9, \mathrm{df}=1, P<0.08)$ due to the combined exposure, revealing a synergistic effect of NICOTINE and ETHANOL. The effect of the combined treatment on \%Time OA was indistinguishable from a simple additivity of the effects of nicotine and ethanol exposure.

For Entries OA + CA (Figure 3e), the ANOVA detected a main TREATMENT effect $(\mathrm{F}=2.9, \mathrm{df}=3, P<0.04)$. Nicotine exposure alone elicited increased locomotor activity when compared to the NIC +ETOH group $(P<0.007$; FPLSD), however, there were no further significant differences between groups. The two-factor analysis of the treatment variables indicated no significant interaction of NICOTINE $\times$ ETHANOL, connoting the fact that the effects of combined exposure were undistinguishable from simple additivity of the effects of nicotine and ethanol.

\section{DISCUSSION}

Tobacco and alcohol consumption are the most commonly abused drugs by teenagers. In spite of the epidemiological association of these drugs in humans, little is known about the possible interactions between them, mainly at the 

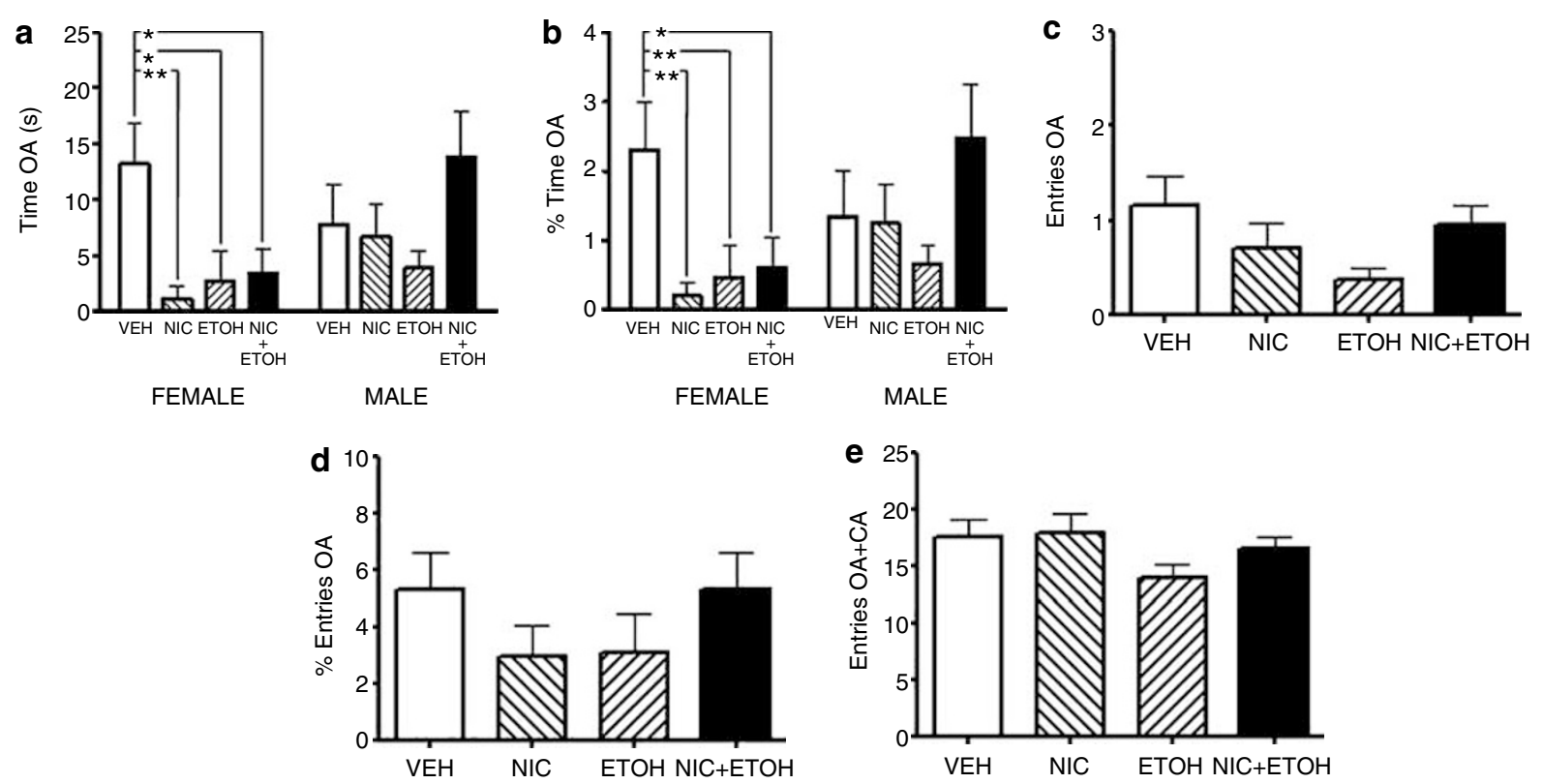

Figure 2 Effects of adolescent nicotine and/or ethanol treatment on anxiety levels (a-d) and locomotor activity (e) measured in the EPM 5 days postexposure (PN50). (a) Time spent in the open arms (Time OA). (b) Percentage of time spent in the open arms (\%Time OA). (c) Number of open arms entries (Entries OA). (d) Percentage of open arms entries (\%Entries OA). (e) Number of open arms + closed arms entries (Entries OA + CA). Values are means \pm SEM. VEH, vehicle group; NIC, nicotine exposure group; ETOH, ethanol exposure group; $\mathrm{NIC}+\mathrm{ETOH}$, nicotine and ethanol exposure group. $* P<0.05$, *** $P<0.01$, significant difference between groups as revealed by FPLSD. Sex differences are shown only where there was a significant treatment $\times$ sex interaction.

critical developmental period of adolescence. The present study provides experimental evidence for functional interactions between nicotine and ethanol in the regulation of behavioral responses, particularly anxiety-related behaviors in adolescent mice.

\section{Methodological Issues}

Rats and some strains of mice have a taste aversion to nicotine. C57BL/6 mice were chosen because prior reports demonstrate that adult and periadolescent mice from this strain consume nicotine in the concentration used in the present study. In fact, oral nicotine has also been shown to be effective in eliciting behavioral (Adriani et al, 2002, 2004; Gaddnas et al, 2001) and neurochemical alterations, including nicotinic receptors upregulation (Nuutinen et al, 2005; Sparks and Pauly, 1999), altered monoamine levels, and metabolism (Gaddnas et al, 2000; Tammimaki et al, 2006; Vihavainen et al, 2006) as well as altered expression of genes implicated in synaptic plasticity induced by drugs of abuse (Marttila et al, 2006) and in Alzheimer's disease (Gutala et al, 2006) in this and other mouse strains. This strain of mice is known to present particular features, such as higher voluntary ethanol consumption (Crawley et al, 1997), which should be taken into consideration in studies that involve the administration of this substance, even though the bases underlying these strain-specific characteristics remain poorly understood (Crabbe et al, 1999). As a result, generalizations should be made with care. In spite of the peculiarities of this strain, significant differences between groups were observed in our study. This fact clearly indicates that there is some fundamental aspect of the neurobiology of these animals that has been differentially affected by the treatment, which should be amenable to further investigation. Accordingly, future studies on the biological bases of ethanol and nicotine interactions are necessary and the use of other strains and species may provide valuable data.

Though nicotine concentration may seem high in the drinking solution, nicotine absorption from the buccal cavity yields cotinine plasma levels (Klein et al, 2003, 2004; Sparks and Pauly, 1999) comparable to those found in adolescent smokers (Binnie et al, 2004; Caraballo et al, 2004; Wood et al, 2004). As for ethanol, according to previous studies in adolescent rodents, even the moderate doses used in the present study result in blood levels well above the legal driving limit (Silveri and Spear, 2000). Ethanol plasma levels are reduced among animals that are simultaneously exposed to ethanol and nicotine (Chen and Harle, 2005; Gilbertson and Barron, 2005; Nowak et al, 1987; Scott et al, 1993). Accordingly, it may be suggested that the less-thanadditive effects of the combined exposure to nicotine and ethanol described in the present study could be due to a reduction in ethanol plasma levels. However, this reduction was only described in animals that received oral ethanol, which led to the suggestion that it is related to a nicotineinduced delay in gastric emptying (Chen and Harle, 2005; Gilbertson and Barron, 2005; Nowak et al, 1987; Scott et al, 1993), causing an increased ethanol metabolization by the gastric alcohol dehydrogenase (Oneta et al, 1998). In fact, other studies indicated that chronic nicotine does not change ethanol concentration if ethanol is infused intravenously (Hisaoka and Levy, 1985). Although we cannot rule out the presence of metabolic nicotine-ethanol interactions; 


\section{PN75}
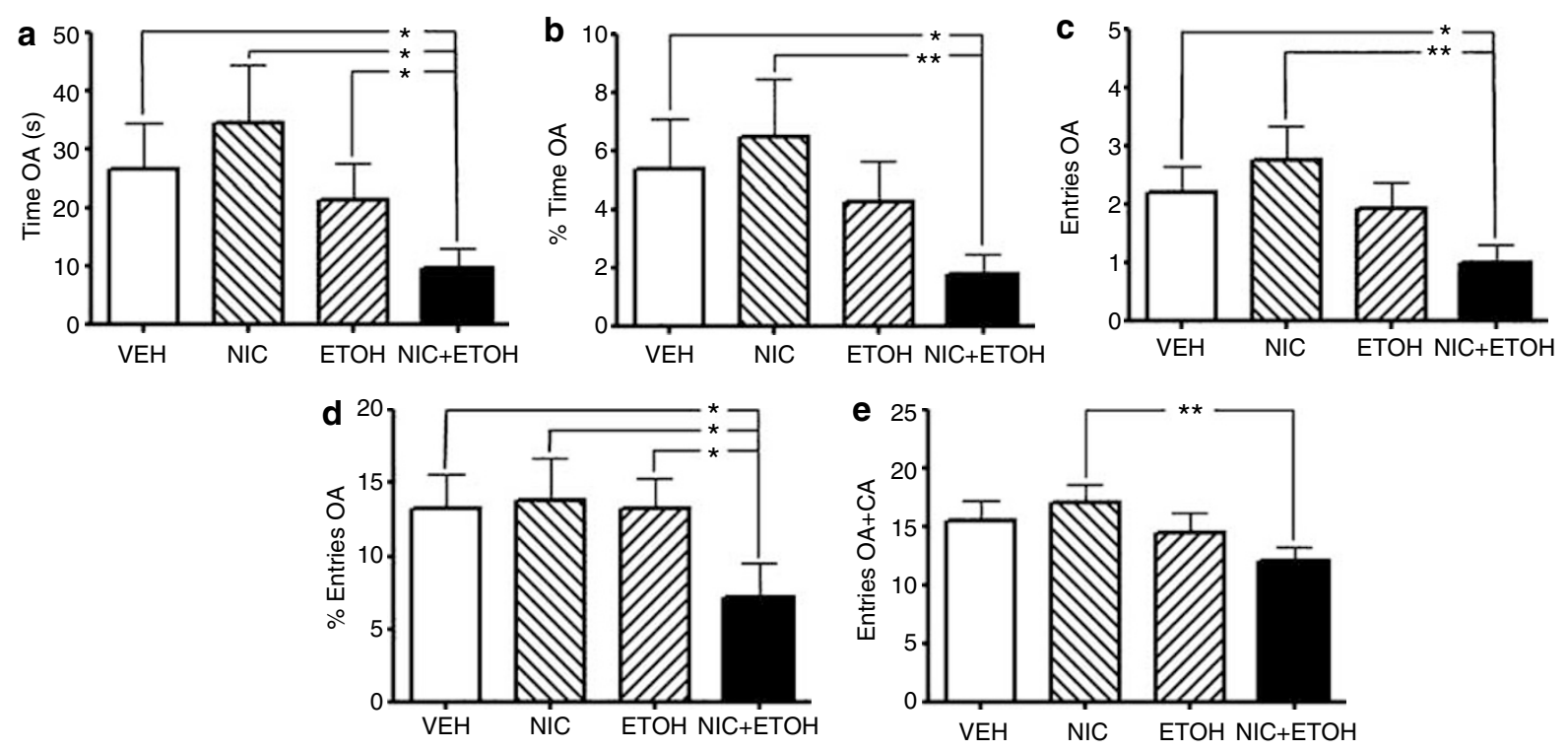

Figure 3 Effects of adolescent nicotine and/or ethanol treatment on anxiety levels (a-d) and locomotor activity (e) measured in the EPM I month postexposure (PN75). (a) Time spent in the open arms (Time OA). (b) Percentage of time spent in the open arms (\%Time OA). (c) Number of open arms entries (Entries OA). (d) Percentage of open arms entries (\%Entries OA). (e) Number of open arms + closed arms entries (Entries OA + CA). Values are means \pm SEM. VEH, vehicle group; NIC, nicotine exposure group; ETOH, ethanol exposure group; $\mathrm{NIC}+\mathrm{ETOH}$, nicotine and ethanol exposure group. $* P<0.05$, ** $P<0.0$ I, significant difference between groups as revealed by FPLSD.

since in the present study we used i.p. ethanol injections, it is unlikely that such metabolic interactions alone can explain the current findings. Additional evidence that nicotine and ethanol interactions do not have a pharmacokinetic origin comes from studies which show that nicotine does not influence the elimination rate of ethanol and vice versa (Collins et al, 1988).

Both nicotine and ethanol exposure elicited a sexdependent female-only reduction in the fluid intake/body weight measure. Furthermore the reduction observed in the nicotine + ethanol group reflected additive effects, which indicated that the female nicotine + ethanol group received somewhat less nicotine than the female nicotine only group. Although we cannot rule out the possibility that these group differences in nicotine consumption influenced the results, only for Time OA and \%Time OA in PN50 were the results of males different from those of females, as indicated by significant TREATMENT $\times$ SEX interactions. However, for both variables, no differences were found between NIC and $\mathrm{NIC}+\mathrm{ETOH}$ groups in both sexes (Figure 2). Furthermore, the absence of sex effects or interactions on all other anxiety measures, the presence of synergistic effects of the combined exposure on PN75, the absence of body weight differences, and the lack of association between the variations in total amount of nicotine consumed and the behavioral variables support the assumption that altered anxiety levels described in the present study cannot be explained by group differences in fluid intake/body weight and/or nicotine consumption.

Our results agree with previous studies that showed that mice are sensitive to the locomotor activating effects of nicotine (Saito et al, 2005; Ulusu et al, 2005). We were concerned that altered activity could influence anxiety measures; accordingly, in addition to using the absolute number of open arms entries as a measure of anxiety, we used the percentage of open arms entries. Whenever we found significant alterations of the absolute number of open arms entries, we also found similar alterations in the percentage of open arms entries, therefore, we are confident that the observed changes in anxiety measures do not reflect changes in locomotor activity.

\section{Anxiolytic Effects during Adolescent Exposure}

The anxiolytic effects of ethanol have been extensively described (Bilkei-Gorzo et al, 1998; Colombo et al, 1995; Ferreira et al, 2000; Gallate et al, 2003; Hall et al, 1998; Martijena et al, 2001; Martin-Garcia and Pallares, 2005; Varlinskaya and Spear, 2002). In fact, although a previous study indicated that adolescent rats may be less sensitive than adults to the anxiolytic effects of ethanol (Varlinskaya and Spear, 2002), a recent study (Hefner and Holmes, 2007) showed that adolescent C57BL/6J mice exhibit increased sensitivity to anxiolytic-like effects of ethanol when compared to adults. Our current results also indicate that ethanol reduces anxiety during adolescence, reinforcing the hypothesis that anxiety could be a critical factor in the etiology of alcohol drinking (Colombo et al, 1995) and extending the period of susceptibility to include adolescence, when alcohol use typically begins. Nicotine exposure has been described as both anxiogenic and anxiolytic (Adriani et al, 2004; Brioni et al, 1993; Cheeta et al, 2001; Elliott et al, 2004; Marco et al, 2006; Ouagazzal et al, 1999; Slawecki et al, 2003). Although we found a trend toward anxiolytic effects of nicotine during adolescent exposure, this failed to reach statistical significance. Previous findings 
in adolescent mice indicate that a lower dose of oral nicotine elicits an anxiogenic response (Adriani et al, 2004). However, our results seem to corroborate recent findings describing that adolescent nicotine does not alter the anxiety state in rats (Marco et al, 2006). However, our results further indicate that the anxiolytic effects of ethanol were reduced by co-exposure with nicotine during adolescence. In light of previous studies on ethanol-nicotine interactions in adult rodents suggesting additive or synergistic anxiolytic effects (depending on the genotype) (Cao et al, 1993); and of contrasting little evidence of interactive effects of nicotine and ethanol during the second postnatal week (Gilbertson and Barron, 2005), our findings provide evidence for adolescence as a critical window for nicotine and ethanol interactions, with unique effects when compared to adulthood and prepubertal periods. More to the point, adolescent nicotine exposure seems to countermand the anxiolytic effect of ethanol consumption. This result raises the question of whether adolescents that coabuse tobacco and ethanol end up consuming more ethanol in order to attain the desired level of anxiolysis. In this regard, experimental studies in rodents have shown that nicotine increases ethanol self-administration and that this response is suppressed by the nicotinic antagonist mecamylamine (Le et al, 2000), which provides evidence for the involvement of nicotinic receptors in the modulation of ethanol consumption.

\section{Anxiogenic Effects during Withdrawal}

Anxiety was suggested to be a symptom of tobacco withdrawal (Hughes et al, 2000; Parrot, 2003). In this sense, the lack of an anxiety effect in males during the 5-day withdrawal due to nicotine or ethanol exposure was somewhat surprising. Regarding nicotine, behavioral alterations in males were expected since it has been already demonstrated that they show more persistent modifications in cholinergic systems, the primary targets of nicotine, after adolescent exposure (Trauth et al, 1999, 2000a). Conversely, our findings show that anxiety levels in females are clearly affected during short-term nicotine withdrawal, a result that is in line with previous findings in rats exposed to this drug during adolescence (Trauth et al, 2000b). Moreover, prospective studies of smokers suggest that lapses during a quit attempt may be a function of anxiety only for females (Dudas et al, 2005). As for ethanol, it is well established that its withdrawal causes anxiogenic responses (File et al, 1993; Kliethermes, 2005). However, despite the fact that adolescents may be hyposensitive to the anxiogenic manifestations of withdrawal, this finding was not described as sex dependent (Doremus et al, 2003; Varlinskaya and Spear, 2004), which is in contrast with the fact that our results show that anxiety levels were only noticeably increased in females. In view of sex differences described above, our results suggest that adolescent female mice are more susceptible to nicotine and ethanol-induced alterations in anxiety levels. Future studies are needed to determine which neurochemical changes are associated with these sexdependent behavioral effects. One possibility is that female-only effects may be hormone dependent. In fact, neuronal cell turnover and plasticity, and hence the effects of agents that affect cell replication, differentiation, and neurite outgrowth, are responsive to estrogen (Tanapat et al, 1999).

Similarly, the combined nicotine + ethanol exposure increased anxiety levels as compared to the VEH only in females. Since nicotine and ethanol exposure elicited anxiogenic profiles, when both drugs were used together, an anxiogenic effect greater than when either drug was used alone could be expected. In spite of this, we found a lessthan-additive effect of nicotine and ethanol. If similar effects occur in human adolescents who co-abuse tobacco and ethanol, then cumulative anxiogenic effects may not play an increased role in relapse to drug use during a shortterm simultaneous smoking and drinking withdrawal.

It is interesting that our results further indicate that nicotine failed to elicit long-lasting changes in anxiety levels, given that previous studies have recently reported that the anxiogenic response to adolescent nicotine persisted up to 1 month postexposure (Slawecki et al, 2003; Smith et al, 2006). However, studies looking at longterm effects of nicotine when administered in adolescents have used rats, as opposed to mice, and these species may differ in the time course of their response to nicotine. As for ethanol, the occurrence of an anxiogenic-like response during long-term withdrawal has been reported in adult rodents (Kliethermes, 2005; Rasmussen et al, 2001; Valdez et al, 2002). However, previous studies either reported longterm increases in anxiety (Slawecki et al, 2004) or hyposensitivity to ethanol effects (Spear and Varlinskaya, 2005) due to exposure during adolescence. The absence of anxiety effects 1 month post-ethanol exposure supports the later finding and are in line with the fact that adolescents differ behaviorally from older animals (Spear, 2002).

In contrast to the lack of effect elicited by either drug, nicotine + ethanol caused an anxiogenic response 1 month after exposure, revealing a synergistic effect of nicotine and ethanol. As a matter of fact, to our knowledge these results constitute the first experimental evidence that the co-abuse does not have a simple additive effect in anxiety levels after long-term withdrawal. In spite of the fact that inherent differences between species make generalization to adolescent human population prone to shortcomings, it is conceivable that if a similar effect occurs after adolescents co-abuse of tobacco and ethanol, the synergistic effect may facilitate relapse to drug use at long-term simultaneous smoking and drinking withdrawal.

\section{Neurobiology of Nicotine $v s$ Ethanol Interactions}

Brain development continues into adolescence, being characterized by continued maturation of neural systems, which encompasses neuroproliferation, apoptosis, and a severe loss of synaptic connections (Altman and Bayer, 1990; Bayer et al, 1982; Bayer, 1983; Huttenlocher, 1990; McWilliams and Lynch, 1983; Rakic et al, 1994). More specifically, the maturation of central cholinergic systems involved in learning, memory, and psychostimulant responses is consolidated during the periadolescent period (Matthews et al, 1974; Nadler et al, 1974; Zahalka et al, 1993), and an important aspect of this period is that neuronal stimulation induces synaptic rearrangement (Scheetz and Constantine-Paton, 1994), which indicates that adolescent brain is vulnerable to central nervous 
system stimulants. As an acetylcholine analog, the nicotinic acetylcholine receptors are the primary cellular mediators of nicotine's effects (Abreu-Villaça et al, 2003, 2004b). As for ethanol, it directly influences the function of various ligandgated ion channels, including nicotinic receptors (for review: Grant, 1994). Accordingly, the nicotinic receptor is a site at which nicotine and ethanol may interact. Corroborating this suggestion, it has been demonstrated that ethanol enhances agonist-induced ion flux through nicotinic receptors (Aistrup et al, 1999; Cardoso et al, 1999) and that ethanol-induced stimulation of mesolimbic dopamine systems involves the activation of nicotinic receptors (Soderpalm et al, 2000). Despite these findings, there have been relatively few animal studies of the basic neurobiology of the combined nicotine and ethanol exposure, and while some studies suggest that nicotine has a modulatory effect on ethanol effects through its cholinergic actions, others show no marked interactions and still others show augmented effects (Bachtell and Ryabinin, 2001; Penland et al, 2001; Tizabi et al, 2002, 2003). Accordingly, the role of cholinergic systems in the anxiety alterations associated with nicotine and ethanol adolescent exposure needs to be tested in subsequent studies. Additionally, neurochemical evidence to date supports the hypothesis that other neurobiological substrates might also underlie adolescent nicotine and ethanol effects on anxiety. In this regard, both ethanol and nicotine (Cousins et al, 2002; Grant, 1994; Slotkin, 2002; Valenzuela, 1997) were shown to interfere with GABAergic and serotonergic systems, and both systems are proposed to partially mediate anxiety effects (Cryan and Kaupmann, 2005; Lowry et al, 2005). Brain regions affected by adolescent nicotine (Abreu-Villaça et al, 2003; Slawecki and Ehlers, 2002; Trauth et al, 2000a) and ethanol (Pascual et al, 2007; White and Swartzwelder, 2004) exposure include the cortex and hippocampus. In fact, several studies have demonstrated that serotonergic and GABAergic systems in the dorsal hippocampus and cortex partially mediate anxiety effects in animal models (Menard and Treit, 1999; Rex et al, 1997; Serra et al, 1999), which suggest that neurotransmitter function alterations in these brain regions could contribute to the behavior alterations observed in the present study. It is also important to note that a growing body of evidence implicates the corticotropin-releasing factor (CRF) systems in the amygdala in anxiety responses. In fact, enhanced CRF release in the amygdala represents a mechanism underlying the anxiogenic and aversive consequences of withdrawal (Menard and Treit, 1999; Merali et al, 1998; Wiersma et al, 1995) common to drugs of abuse such as nicotine (Slawecki et al, 2005) and ethanol (Merlo Pich et al, 1995; Rivier, 1996).

The fact that both nicotine and ethanol target similar neurotransmitter systems raises the possibility of less-thanadditive or synergistic interactions between the two treatments, and indeed, we observed both types of effects. In general, during exposure, the combined treatment elicited less-than-additive effects: the anxiolytic effects of ethanol were reduced by co-exposure with nicotine. During withdrawal, initially, the combined exposure elicited increased anxiety levels which, still, reflected less-thanadditive effects, however, 1 month postexposure, the anxiogenic results mainly reflected synergistic effects of nicotine and ethanol.

\section{Conclusions}

Human adolescent tobacco and ethanol consumption are severe public health issues, the effects of which are detectable into adulthood. Accordingly, it is important to characterize behavioral alterations shared by these two drugs as a step toward understanding the mechanisms of nicotine and ethanol coadministration. Our results show that ethanol is anxiolytic in adolescent mice and that nicotine reverts this effect. Therefore, it is possible that, contrasting with previous suggestions (Cao et al, 1993; deFiebre and Collins, 1992), in our experimental setup, the association between nicotine and ethanol consumption may not be explained by cumulative anxiety effects. In spite of the fact that generalization to the adolescent human population should be carried out with care due to inherent differences between species, it would be interesting to study in adolescent humans, who may adjust their consumption according to their will, whether the blunted anxiolytic effect of ethanol caused by co-exposure to tobacco drive higher ethanol consumption.

Additionally, although neither nicotine nor ethanol effects persisted up to 1 month postexposure, our data provide evidence that adolescents who combine nicotine and ethanol consumption become anxious adults in the prolonged absence of these drugs. Anxiety is a critical factor for nicotine and ethanol use due to its motivating force for a continued consumption (Colombo et al, 1995; Gilbert et al, 1989; Picciotto et al, 2002; Pomerleau, 1986). Accordingly, our present findings indicate that nicotine and ethanol interact during adolescence altering anxiety levels throughout life. The C57BL/6 strain of mice is known to present peculiar features in both behavior and neurobiology. As a result, generalizations should be made with care. In any case, if a similar effect occurs after adolescents co-abuse of tobacco and ethanol, then it may facilitate relapse to drug use at long-term simultaneous smoking and drinking withdrawal.

\section{ACKNOWLEDGEMENTS}

This work was supported by grants from Philip Morris USA Inc. and Philip Morris International, Conselho Nacional de Desenvolvimento Científico e Tecnológico (CNPq-BRAZIL), and by fellowships from Fundação de Amparo à Pesquisa do Estado do Rio de Janeiro (FAPERJ-BRAZIL) and Subreitoria de Pós-graduação e Pesquisa da Universidade do Estado do Rio de Janeiro (SR2-UERJ). We are thankful to Armando Meyer for helpful comments and to Edson Oliveira for animal care.

\section{DISCLOSURE/CONFLICT OF INTEREST}

None of the authors receive personal compensation from Philip Morris USA Inc. and Philip Morris International. Furthermore, the agreement between the authors and Philip Morris USA Inc. and Philip Morris International strongly encourages the publication of results in the open scientific literature, without prior restrictions or consultation. The authors have no other conflicts of interest to declare. 


\section{REFERENCES}

Abreu-Villaça Y, Seidler F, Slotkin TA (2004a). Does prenatal nicotine exposure sensitize the brain to nicotine-induced neurotoxicity in adolescence? Neuropsychopharmacology 29: 1440-1450.

Abreu-Villaça Y, Seidler FJ, Qiao D, Tate CA, Cousins MM, Thillai I et al (2003). Short-term adolescent nicotine exposure has immediate and persistent effects on cholinergic systems: critical periods, patterns of exposure, dose thresholds. Neuropsychopharmacology 28: 1935-1949.

Abreu-Villaça Y, Seidler FJ, Tate CA, Cousins MM, Slotkin TA (2004b). Prenatal nicotine exposure alters the response to nicotine administration in adolescence: effects on cholinergic systems during exposure and withdrawal. Neuropsychopharmacology 29: 879-890.

Adriani W, Granstrem O, Macri S, Izykenova G, Dambinova S, Laviola G (2004). Behavioral and neurochemical vulnerability during adolescence in mice: studies with nicotine. Neuropsychopharmacology 29: 869-878.

Adriani W, Macri S, Pacifici R, Laviola G (2002). Peculiar vulnerability to nicotine oral self-administration in mice during early adolescence. Neuropsychopharmacology 27: 212-224.

Aistrup GL, Marszalec W, Narahashi T (1999). Ethanol modulation of nicotinic acetylcholine receptor currents in cultured cortical neurons. Mol Pharmacol 55: 39-49.

Altman J, Bayer SA (1990). Migration and distribution of two populations of hippocampal granule cell precursors during the perinatal and postnatal periods. J Comp Neurol 301: 365-381.

Bachtell RK, Ryabinin AE (2001). Interactive effects of nicotine and alcohol co-administration on expression of inducible transcription factors in mouse brain. Neuroscience 103: 941-954.

Balerio GN, Aso E, Maldonado R (2006). Role of the cannabinoid system in the effects induced by nicotine on anxiety-like behaviour in mice. Psychopharmacology 184: 504-513.

Bayer SA (1983). [ $\left.{ }^{3} \mathrm{H}\right]$ Thymidine-radiographic studies of neurogenesis in the rat olfactory bulb. Exp Brain Res 50: 329-340.

Bayer SA, Yackel JW, Puri PS (1982). Neurons in the rat dentate gyrus granular layer substantially increase during juvenile and adult life. Science 216: 890-892.

Bilkei-Gorzo A, Gyertyan I, Levay G (1998). mCPP-induced anxiety in the light-dark box in rats-a new method for screening anxiolytic activity. Psychopharmacology 136: 291-298.

Binnie V, McHugh S, Macpherson L, Borland B, Moir K, Malik K (2004). The validation of self-reported smoking status by analysing cotinine levels in stimulated and unstimulated saliva, serum and urine. Oral Dis 10: 287-293.

Brioni JD, O’Neill AB, Kim DJ, Decker MW (1993). Nicotinic receptor agonists exhibit anxiolytic-like effects on the elevated plus-maze test. Eur J Pharmacol 238: 108.

Cao W, Burkholder T, Wilkins L, Collins AC (1993). A genetic comparison of behavioral actions of ethanol and nicotine in the mirrored chamber. Pharmacol Biochem Behav 45: 803-809.

Caraballo RS, Giovino GA, Pechacek TF (2004). Self-reported cigarette smoking $v s$ serum cotinine among US adolescents. Nicotine Tob Res 6: 19-25.

Cardoso RA, Brozowski SJ, Chavez-Noriega LE, Harpold M, Valenzuela CF, Harris RA (1999). Effects of ethanol on recombinant human neuronal nicotinic acetylcholine receptors expressed in Xenopus oocytes. J Pharmacol Exp Ther 289: 774-780.

Carmody TP, Brischetto CS, Matarazzo JD, O'Donnell RP, Connor WE (1985). Co-occurrent use of cigarettes, alcohol, and coffee in healthy, community-living men and women. Health Psychol 4: 323-335.

Carobrez AP, Bertoglio LJ (2005). Ethological and temporal analyses of anxiety-like behavior: the elevated plus-maze model 20 years on. Neurosci Biobehav Rev 29: 1193-1205.

Cheeta S, Irvine EE, Tucci S, Sandhu J, File SE (2001). In adolescence, female rats are more sensitive to the anxiolytic effect of nicotine than are male rats. Neuropsychopharmacology 25: 601-607.
Chen WJ, Harle LK (2005). Interactive effect of alcohol and nicotine on developing cerebellum: an investigation of the temporal pattern of alcohol and nicotine administration. Alcohol Clin Exp Res 29: 437-442.

Collins AC, Burch JB, de Fiebre CM, Marks MJ (1988). Tolerance to and cross tolerance between ethanol and nicotine. Pharmacol Biochem Behav 29: 365-373.

Colombo G, Agabio R, Lobina C, Reali R, Zocchi A, Fadda F et al (1995). Sardinian alcohol-preferring rats: a genetic animal model of anxiety. Physiol Behav 57: 1181-1185.

Cousins MS, Roberts DC, de Wit H (2002). GABA(B) receptor agonists for the treatment of drug addiction: a review of recent findings. Drug Alcohol Depend 65: 209-220.

Crabbe JC, Phillips TJ, Buck KJ, Cunningham CL, Belknap JK (1999). Identifying genes for alcohol and drug sensitivity: recent progress and future directions. Trends Neurosci 22: 173-179.

Crawley JN, Belknap JK, Collins A, Crabbe JC, Frankel W, Henderson $\mathrm{N}$ et al (1997). Behavioral phenotypes of inbred mouse strains: implications and recommendations for molecular studies. Psychopharmacology (Berl) 132: 107-124.

Cryan JF, Kaupmann K (2005). Don't worry 'B' happy!: a role for GABA(B) receptors in anxiety and depression. Trends Pharmacol Sci 26: 36-43.

Dawson DA (2000). Drinking as a risk factor for sustained smoking. Drug Alcohol Depend 59: 235-249.

deFiebre CM, Collins AC (1992). Alcohol-nicotine actions and interactions: studies in humans and animals. In: Watson RR (ed). Alcohol and Neurobiology: Brain Development and Hormone Regulation. CRC Press: Boca Raton, FL. pp 305-339.

DiFranza JR, Guerrera MP (1990). Alcoholism and smoking. J Stud Alcohol 51: 130-135.

Doremus TL, Brunell SC, Varlinskaya EI, Spear LP (2003). Anxiogenic effects during withdrawal from acute ethanol in adolescent and adult rats. Pharmacol Biochem Behav 75: 411-418.

Douglas LA, Varlinskaya EI, Spear LP (2003). Novel-object place conditioning in adolescent and adult male and female rats: effects of social isolation. Physiol Behav 80: 317-325.

Dudas RB, Hans K, Barabas K (2005). Anxiety, depression and smoking in schoolchildren - implications for smoking prevention. J R Soc Health 125: 87-92.

Elliott BM, Faraday MM, Phillips JM, Grunberg NE (2004). Effects of nicotine on elevated plus maze and locomotor activity in male and female adolescent and adult rats. Pharmacol Biochem Behav 77: 21-28.

Ferandes C, File SE (1996). The influence of open arm ledges and maze experience in the elevated-plus maze. Pharmacol Biochem Behav 54: 31-40.

Ferreira VM, Takahashi RN, Morato GS (2000). Dexamethasone reverses the ethanol-induced anxiolytic effect in rats. Pharmacol Biochem Behav 66: 585-590.

File SE, Andrews N, al-Farhan M (1993). Anxiogenic responses of rats on withdrawal from chronic ethanol treatment: effects of tianeptine. Alcohol Alcohol 28: 281-286.

Gaddnas H, Pietila K, Ahtee L (2000). Effects of chronic oral nicotine treatment and its withdrawal on locomotor activity and brain monoamines in mice. Behaviour Brain Res 113: 65-72.

Gaddnas H, Pietila K, Piepponen TP, Ahtee L (2001). Enhanced motor activity and brain dopamine turnover in mice during long-term nicotine administration in the drinking water. Pharmacol Biochem Behav 70: 497-503.

Gallate JE, Morley KC, Ambermoon P, McGregor IS (2003). The consequences of beer consumption in rats: acute anxiolytic and ataxic effects and withdrawal-induced anxiety. Psychopharmacology (Berl) 166: 51-60.

Gilbert DG, Robinson JH, Chamberlin CL, Spielberger CD (1989). Effects of smoking/nicotine on anxiety, heart rate, and lateralization of EEG during a stressful movie. Psychophysiology 26: $311-320$. 
Gilbertson RJ, Barron S (2005). Neonatal ethanol and nicotine exposure causes locomotor activity changes in preweanling animals. Pharmacol Biochem Behav 81: 54-64.

Grant BF (1998). Age at smoking onset and its association with alcohol consumption and DSM-IV alcohol abuse and dependence: results from the national longitudinal alcohol epidemiologic survey. J Substance Abuse 10: 59-73.

Grant KA (1994). Emerging neurochemical concepts in the actions of ethanol at ligand-gated ion channels. Behav Pharmacol 5: 383-404.

Gutala R, Wang J, Hwang YY, Haq R, Li MD (2006). Nicotine modulates expression of amyloid precursor protein and amyloid precursor-like protein 2 in mouse brain and in SH-SY5Y neuroblastoma cells. Brain Res 1093: 12-19.

Hall FS, Huang S, Fong GW, Pert A, Linnoila M (1998). Effects of isolation-rearing on locomotion, anxiety and responses to ethanol in Fawn Hooded and Wistar rats. Psychopharmacology 139: 203-209.

Hefner K, Holmes A (2007). An investigation of the behavioral actions of ethanol across adolescence in mice. Psychopharmacology (Berl) 191: 311-322.

Hisaoka M, Levy G (1985). Kinetics of drug action in disease states XI: effect of nicotine on the pharmacodynamics and pharmacokinetics of phenobarbital and ethanol in rats. J Pharm Sci 74: 412-415.

Hogg S (1996). A review of the validity and variability of the elevated plus maze as an animal model of anxiety. Pharmacol Biochem Behav 54: 21-30.

Hughes JR, Stead LF, Lancaster T (2000). Anxiolytics for smoking cessation. Cochrane Database Syst Rev 4: CD002849.

Huttenlocher PR (1990). Morphometric study of human cerebral cortex development. Neuropsychologia 28: 517-527.

Klein LC, Stine MM, Pfaff DW, Vandenbergh DJ (2003). Maternal nicotine exposure increases nicotine preference in periadolescent male but not female C57B1/6J mice. Nicotine Tobacco Res 5: 117-124.

Klein LC, Stine MM, Vandenbergh DJ, Whetzel CA, Kamens HM (2004). Sex differences in voluntary oral nicotine consumption by adolescent mice: a dose-response experiment. Pharmacol Biochem Behav 78: 13-25.

Kliethermes CL (2005). Anxiety-like behaviors following chronic ethanol exposure. Neurosci Biobehav Rev 28: 837-850.

Larsson A, Engel JA (2004). Neurochemical and behavioral studies on ethanol and nicotine interactions. Neurosci Biobehav Rev 27: 713-720.

Le AD, Corrigall WA, Harding JW, Juzytsch W, Li TK (2000). Involvement of nicotinic receptors in alcohol self-administration. Alcohol Clin Exp Res 24: 155-163.

Lowry CA, Johnson PL, Hay-Schmidt A, Mikkelsen J, Shekhar A (2005). Modulation of anxiety circuits by serotonergic systems. Stress 8: 233-246.

Marco EM, Llorente R, Moreno E, Biscaia JM, Guaza C, Viveros MP (2006). Adolescent exposure to nicotine modifies acute functional responses to cannabinoid agonists in rats. Behav Brain Res 172: 46-53.

Martijena ID, Lacerra C, Bustos SG, Molina VA (2001). Chronic benzodiazepine administration facilitates the subsequent development of ethanol dependence. Brain Res 891: 236-246.

Martin-Garcia E, Pallares M (2005). Intrahippocampal nicotine and neurosteroids effects on the anxiety-like behaviour in voluntary and chronic alcohol-drinking rats. Behav Brain Res 164: 117-127.

Marttila K, Raattamaa H, Ahtee L (2006). Effects of chronic nicotine administration and its withdrawal on striatal FosB/ DeltaFosB and c-Fos expression in rats and mice. Neuropharmacology 51: 44-51.

Matthews DA, Nadler JV, Lynch GS, Cotman CW (1974). Development of cholinergic innervation in the hippocampal formation of the rat. Dev Biol 36: 130-141.
McWilliams JR, Lynch G (1983). Rate of synaptic replacement in denervated rat hippocampus declines precipitously from the juvenile period to adulthood. Science 221: 572-574.

Menard J, Treit D (1999). Effects of centrally administered anxiolytic compounds in animal models of anxiety. Neurosci Biobehav Rev 23: 591-613.

Merali Z, McIntosh J, Kent P, Michaud D, Anisman H (1998). Aversive and appetitive events evoke the release of corticotropin releasing hormone and bombesin-like peptides at the central nucleus of the amygdala. J Neurosci 18: 4758-4766.

Merlo Pich EM, Lorang M, Yeganeh M, Rodriguez de Fonseca F, Raber J, Koob GF et al (1995). Increase of extracellular corticotropin-releasing factor-like immunoreactivity levels in the amygdala of awake rats during restraint stress and ethanol withdrawal as measured by microdialysis. J Neurosci 15: 5439-5447.

Nadler JV, Matthews DA, Cotman CW, Lynch GS (1974). Development of cholinergic innervation in the hippocampal formation of the rat. II. Quantitative changes in choline acetyltransferase and acetylcholinesterase activities. Dev Biol 36: $142-154$.

National Institute on Drug Abuse (1998). Nicotine Addiction. NIH Publication Number 98-4342. Washington, DC, 7pp.

Nelson DE, Giovino GA, Shopland DR, Mowery PD, Mills SL, Eriksen MP (1995). Trends in cigarette smoking among US adolescents, 1974 through 1991. Am J Public Health 85: 34-40.

Nowak A, Jonderko K, Kaczor R, Nowak S, Skrzypek D (1987). Cigarette smoking delays gastric emptying of a radiolabelled solid food in healthy smokers. Scand J Gastroenterol 22: 54-58.

Nuutinen S, Ahtee L, Tuominen RK (2005). Time and brain region specific up-regulation of low affinity neuronal nicotinic receptors during chronic nicotine administration in mice. Eur $J$ Pharmacol 515: 83-89.

Oneta CM, Simanowski UA, Martinez M, Allali-Hassani A, Parés X, Homann $\mathrm{N}$ et al (1998). First pass metabolism of ethanol is strikingly influenced by the speed of gastric emptying. Gut 43: 612-619.

Ouagazzal AM, Kenny PJ, File SE (1999). Modulation of behaviour on trials 1 and 2 in the elevated-plus-maze test of anxiety after systemic and hippocampal administration of nicotine. Psychopharmacology 144: 54-60.

Parrot AC (2003). Cigarette-derived nicotine is not a medicine. World J Biol Psychiatry 4: 49-55.

Pascual M, Blanco AM, Cauli O, Minarro J, Guerri C (2007). Intermittent ethanol exposure induces inflammatory brain damage and causes long-term behavioural alterations in adolescent rats. Eur J Neurosci 25: 541-550.

Patten CA, Martin JE, Owen N (1996). Can psychiatric and chemical dependency treatment units be smoke free? J Subst Abuse Treat 13: 107-118.

Penland S, Hoplight B, Obernier J, Crews FT (2001). Effects of nicotine on ethanol dependence and brain damage. Alcohol 24: 45-54.

Picciotto MR, Brunzell DH, Caldarone BJ (2002). Effect of nicotine and nicotinic receptors on anxiety and depression. Neuroreport 13: $1097-1106$.

Pomerleau OF (1986). Nicotine as a psychoactive drug: anxiety and pain reduction. Psychopharmacol Bull 22: 865-869.

Popovic M, Caballero-Bleda M, Puelles L, Guerri C (2004). Multiple binge alcohol consumption during rat adolescence increases anxiety but does not impair retention in the passive avoidance task. Neurosci Lett 357: 79-82.

Rakic P, Bourgeois JP, Goldman-Rakic PS (1994). Synaptic development of the cerebral cortex: implications for learning, memory, and mental illness. Prog Brain Res 102: 227-243.

Rasmussen DD, Mitton DR, Green J, Puchalski S (2001). Chronic daily ethanol and withdrawal: 2. Behavioral changes during prolonged abstinence. Alcohol Clin Exp Res 25: 999-1005. 
Rex A, Marsden CA, Fink H (1997). Cortical 5-HT-CCK interactions and anxiety-related behaviour in guinea pigs: a microdialysis study. Neurosci Lett 228: 79-82.

Rhodes MC, Seidler FJ, Qiao D, Tate CA, Cousins MM, Thillai I et al (2003). Does pharmacotherapy for preterm labor sensitize the developing brain to environmental neurotoxicants? Cellular and synaptic effects of sequential exposure to terbutaline and chlorpyrifos in neonatal rats. Toxicol Appl Pharmacol 195: 203-217.

Rivier C (1996). Alcohol stimulates ACTH secretion in the rat: mechanisms of action and interactions with other stimuli. Alcohol Clin Exp Res 20: 240-254.

Rodgers RJ, Dalvi DA (1997). Anxiety defence and the elevated plus maze. Neurosci Biobehav Rev 21: 801-810.

Saito M, O'Brien D, Kovacs KM, Wang R, Zavadil J, Vadasz C (2005). Nicotine-induced sensitization in mice: changes in locomotor activity and mesencephalic gene expression. Neurochem Res 30: 1027-1035.

Scheetz AJ, Constantine-Paton M (1994). Modulation of NMDA receptor function: implications for vertebrate neural development. FASEB J 8: 745-752.

Scott AM, Kellow JE, Shuter B, Nolan JM, Hoschl R, Jones MP (1993). Effects of cigarette smoking on solid and liquid intragastric distribution and gastric emptying. Gastroenterology 104: $410-416$.

Serra M, Concas A, Mostallino MC, Chessa MF, Stomati M, Petraglia F et al (1999). Antagonism of stress-induced changes in GABAA receptor function and corticotropin-releasing factor concentration in rat brain. Psychoneuroendocrinology 24: 269-284.

Silveri MM, Spear LP (2000). Ontogeny of ethanol elimination and ethanol-induced hypothermia. Alcohol 20: 45-53.

Slawecki CJ, Ehlers CL (2002). Lasting effects of adolescent nicotine exposure on the electroencephalogram, event related potentials, and locomotor activity in the rat. Dev Brain Res 138: 15-25.

Slawecki CJ, Ehlers CL (2005). Enhanced prepulse inhibition following adolescent ethanol exposure in Sprague-Dawley rats. Alcohol Clin Exp Res 29: 1829-1836.

Slawecki CJ, Gilder A, Roth J, Ehlers CL (2003). Increased anxietylike behavior in adult rats exposed to nicotine as adolescents. Pharmacol Biochem Behav 75: 355-361.

Slawecki CJ, Thorsell A, Ehlers CL (2004). Long-term neurobehavioral effects of alcohol or nicotine exposure in adolescent animal models. Ann NY Acad Sci 1021: 448-452.

Slawecki CJ, Thorsell AK, El Khoury A, Mathé AA, Ehlers CL (2005). Increased CRF-like and NPY-like immunoreactivity in adult rats exposed to nicotine during adolescence: relation to anxiety-like and depressive-like behavior. Neuropeptides 39: 369-377.

Slotkin TA (2002). Nicotine and the adolescent brain: insights from an animal model. Neurotoxicol Teratol 24: 369-384.

Smith LN, McDonald CG, Bergstrom HC, Brielmaier JM, Eppolito $\mathrm{AK}$, Wheeler TL et al (2006). Long-term changes in fear conditioning and anxiety-like behavior following nicotine exposure in adult $v s$ adolescent rats. Pharmacol Biochem Behav 85: 91-97.

Snedecor GW, Cochran WG (1967). Statistical Methods, 6th edn. Iowa State University Press, Iowa.

Soderpalm B, Ericson M, Olausson P, Blomqvist O, Engel JA (2000). Nicotinic mechanisms involved in the dopamine activating and reinforcing properties of ethanol. Behav Brain Res 113: 85-96.

Sparks JA, Pauly JR (1999). Effects of continuous oral nicotine administration on brain nicotinic receptors and responsiveness to nicotine in C57B1/6 mice. Psychopharmacology 141: 145-153.

Spear L (2000). Modeling adolescent development and alcohol use in animals. Alcohol Res Health 24: 115-123.
Spear LP (2002). The adolescent brain and the college drinker: biological basis of propensity to use and misuse alcohol. J Stud Alcohol Suppl 14: 71-81.

Spear LP, Varlinskaya EI (2005). Adolescence. Alcohol sensitivity, tolerance, and intake. Recent Dev Alcohol 17: 143-159.

Tammimaki A, Pietila K, Raattamaa H, Ahtee L (2006). Effect of quinpirole on striatal dopamine release and locomotor activity in nicotine-treated mice. Eur J Pharmacol 531: 118-125.

Tanapat P, Hastings NB, Reeves AJ, Gould E (1999). Estrogen stimulates a transient increase in the number of new neurons in the dentate gyrus of the adult female rat. J Neurosci 19: 5792-5801.

Tizabi Y, Al-Namaeh M, Manaye KF, Taylor RE (2003). Protective effects of nicotine on ethanol-induced toxicity in cultured cerebellar granule cells. Neurotox Res 5: 315-321.

Tizabi Y, Copeland RLJ, Louis VA, Taylor RE (2002). Effects of combined systemic alcohol and central nicotine administration into ventral tegmental area on dopamine release in the nucleus accumbens. Alcohol Clin Exp Res 26: 394-399.

Trauth JA, McCook EC, Seidler FJ, Slotkin TA (2000a). Modeling adolescent nicotine exposure: effects on cholinergic systems in rat brain regions. Brain Res 873: 18-25.

Trauth JA, Seidler FJ, McCook EC, Slotkin TA (1999). Adolescent nicotine exposure causes persistent upregulation of nicotinic cholinergic receptors in rat brain regions. Brain Res 851: 9-19.

Trauth JA, Seidler FJ, Slotkin TA (2000b). Persistent and delayed behavioral changes after nicotine treatment in adolescent rats. Brain Res 880: 167-172.

Ulusu U, Uzbay IT, Kayir H, Alici T, Karakas S (2005). Evidence for the role of nitric oxide in nicotine-induced locomotor sensitization in mice. Psycopharmacology (Berl) 178: 500-504.

Valdez GR, Roberts AJ, Chan K, Davis H, Brennan M, Zorrilla EP et al (2002). Increased ethanol self-administration and anxietylike behavior during acute ethanol withdrawal and protracted abstinence: regulation by corticotropin-releasing factor. Alcohol Clin Exp Res 26: 1494-1501.

Valenzuela CF (1997). Alcohol and neurotransmitter interactions. Alcohol Res Health 21: 144-148.

Vanderschuren LJ, Niesink RJ, Van Ree JM (1997). The neurobiology of social play behavior in rats. Neurosci Biobehav Rev 21: 309-326.

Varlinskaya EI, Spear LP (2002). Acute effects of ethanol on social behavior of adolescent and adult rats: role of familiarity of the test situation. Alcohol Clin Exp Res 26: 1502-1511.

Varlinskaya EI, Spear LP (2004). Acute ethanol withdrawal (hangover) and social behavior in adolescent and adult male and female Sprague-Dawley rats. Alcohol Clin Exp Res 28: $40-50$.

Vihavainen T, Mijatovic J, Piepponen TP, Tuominen RK, Ahtee L (2006). Effect of morphine on locomotor activity and striatal monoamine metabolism in nicotine-withdrawn mice. Behav Brain Res 173: 85-93.

White AM, Swartzwelder HS (2004). Hippocampal function during adolescence: a unique target of ethanol effects. Ann NY Acad Sci 1021: 206-220.

Wiersma A, Baauw AD, Bohus B, Koolhaas JM (1995). Behavioral activation produced by CRH but not alpha-helical CRH (CRH receptor antagonist) when microinfused into the central nucleus of the amygdale under stress-free conditions. Psychoneuroendocrinology 20: 423-432.

Wood T, Wewers ME, Groner J, Ahijevych K (2004). Smoke constituent exposure and smoking topography of adolescent daily cigarette smokers. Nicotine Tob Res 6: 853-862.

Zahalka E, Seidler FJ, Lappi SE, Yanai J, Slotkin TA (1993). Differential development of cholinergic nerve terminal markers in rat brain regions: implications for nerve terminal density, impulse activity and specific gene expression. Brain Res 601: 221-229. 